\title{
Clinical Trial Considerations in Neuro-oncology
}

\section{Eudocia Q. Lee, MD, MPH॰}

\author{
Address \\ Center for Neuro-Oncology, Dana-Farber Cancer Institute, Boston, MA, 02215, \\ USA \\ Email: eqlee@partners.org
}

Published online: 2 July 2021

(C) The Author(s), under exclusive licence to Springer Science+Business Media, LLC, part of Springer Nature 2021

\section{This article is part of the Topical Collection on Neuro-oncology}

Keywords Clinical trials · Clinical trial disparities · Clinical trial accrual · Clinical trial design · Response assessment

\section{Opinion statement}

Clinical trials play a critical role in discovering new treatments, but the path to regulatory approval can be cumbersome and time consuming. Efforts to increase the efficiency and interpretability of clinical trials within the neuro-oncology community have focused on standardization of response assessment, development of consensus guidelines for clinical trial conduct, decentralization of clinical trials, removal of barriers to clinical trial accrual, and re-examination of patient eligibility criteria.

\section{Introduction}

Clinical trials play a critical role in discovering new treatments. Over the past decade, the neuro-oncology community has worked on improving the design, interpretation, accrual, and conduct of clinical trials. The effort has been spearheaded predominantly by the Response Assessment in Neuro-Oncology (RANO) working group, a multidisciplinary international working group consisting of neuro-oncologists, medical oncologists, neuroradiologists, neurosurgeons, radiation oncologists, neuropsychologists, and experts in clinical outcomes assessments, working in collaboration with government and industry. Their initial papers focused on the limitations of endpoint assessments in gliomas [1] and updating response criteria for high-grade glioma [2], which has now become the standard method for radiographic assessment in high-grade glioma clinical trials. Over the past decade, RANO efforts have expanded into other central nervous system (CNS) tumors including low-grade gliomas, meningiomas, brain metastases, leptomeningeal metastases, pediatric CNS tumors, and spine tumors as well as other aspects of response assessment including seizure endpoints, standardization of neurologic examination assessment, use of PET imaging, the impact of immunotherapy in response assessment, corticosteroid use, pathologic assessments, and patient-reported outcomes (Table 1). More recently, RANO has collaborated with the Society for Neuro-Oncology (SNO), patient advocacy groups, clinical trial cooperative groups, and other partners to in-

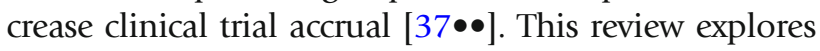


Table 1. Clinical trial outcome assessments and guidelines developed by RANO working groups

\begin{tabular}{|c|c|}
\hline Name of working group & Reports/guidelines published to date \\
\hline RANO HGG (high-grade glioma) & $\begin{array}{l}\text { - Limitations of endpoint assessments for high-grade gliomas [3] } \\
\text { - Proposed response assessment criteria for high-grade glioma [2] } \\
\text { - Clinical trial design and endpoints }[4,5] \\
\text { - Challenges in brain tumor related phase } 0 \text { and window of opportunity clinical trials } \\
\text { [6•] }\end{array}$ \\
\hline iRANO (immunotherapy) & $\begin{array}{l}\text { - Proposed radiographic response assessment for brain tumor patients receiving } \\
\text { immunotherapy [7] }\end{array}$ \\
\hline RANO LGG (low-grade glioma) & - Proposed response assessment criteria for low-grade glioma [3] \\
\hline $\begin{array}{l}\text { Response Assessment in Pediatric } \\
\text { Neuro-Oncology (RAPNO) }\end{array}$ & $\begin{array}{l}\text { - Challenges in pediatric neuro-oncology clinical trials [8] } \\
\text { - Proposed response assessment in pediatric medulloblastoma and leptomeningeal } \\
\text { seeding tumors [9] } \\
\text { - Proposed response assessment in pediatric high-grade glioma [10] } \\
\text { - Proposed response assessment in pediatric low-grade glioma [11] } \\
\text { - Proposed response assessment in pediatric diffuse intrinsic pontine glioma [12] }\end{array}$ \\
\hline RANO BM (brain metastases) & $\begin{array}{l}\text { - Challenges in brain metastases clinical trials }[13,14] \\
\text { - Proposed response assessment criteria for brain metastases [15] } \\
\text { - Clinical trial design and endpoints for systemic therapies [16] and local therapies } \\
\text { [17] }\end{array}$ \\
\hline RANO LM (leptomeningeal disease) & $\begin{array}{l}\text { - Review of challenges in leptomeningeal disease clinical trials [18] } \\
\text { - Proposal for response assessment criteria for leptomeningeal metastases [19] } \\
\text { - Revised proposal for response assessment criteria for leptomeningeal metastases } \\
\text { [20] }\end{array}$ \\
\hline RANO Meningioma & $\begin{array}{l}\text { - Review of PFS6 benchmarks in meningioma clinical trials [21] } \\
\text { - Review of meningioma treatments and patient outcomes following standard surgery } \\
\text { and radiotherapy to help inform clinical trial design [22] }\end{array}$ \\
\hline $\begin{array}{l}\text { Neurologic Assessment in } \\
\text { Neuro-Oncology (NANO) }\end{array}$ & - Standardized neurologic assessment metric for clinical trials [23] \\
\hline RANO Seizures & - Proposed seizure assessment as a metric in brain tumor treatment trials [24] \\
\hline $\begin{array}{l}\text { SPIne response assessment in } \\
\text { Neuro-Oncology (SPINO) }\end{array}$ & $\begin{array}{l}\text { - Challenges in standardizing imaging-based assessment of local control and pain for } \\
\text { spinal metastases [25] } \\
\text { - Proposed response assessment following spine stereotactic body radiotherapy for } \\
\text { spinal metastases [25] } \\
\text { - Recommendations for patient- and clinician-reported measures in clinical trials for } \\
\text { spinal metastases [26] }\end{array}$ \\
\hline RANO Steroid & $\begin{array}{l}\text { - Recommendations for evaluating corticosteroid use in endpoint assessment for } \\
\text { clinical trials [27] }\end{array}$ \\
\hline $\begin{array}{l}\text { RANO Patient Reported Outcomes } \\
\text { (PRO) }\end{array}$ & $\begin{array}{l}\text { - Guidance on the use of patient-reported outcome measures in clinical trials and } \\
\text { practice for adult patients with brain tumors [28] } \\
\text { - Consensus recommendations for core set of symptom and functional constructs as } \\
\text { represented in existing PRO measures for use in clinical care and trials for patients with } \\
\text { high-grade gliomas [29] }\end{array}$ \\
\hline RANO PET & $\begin{array}{l}\text { - Recommendations for use of PET imaging in gliomas [30, 31] } \\
\text { - Recommendations for use of PET imaging in meningiomas [32] } \\
\text { - Recommendations for use of PET imaging in brain metastases [33] }\end{array}$ \\
\hline RANO Surgery & - Recommendations for surgically related endpoint assessment [34] \\
\hline
\end{tabular}


Table 1. (Continued)

$\begin{array}{ll}\text { Name of working group } & \text { Reports/guidelines published to date } \\ \text { RANO Pathology } & \begin{aligned} \text { Standardization of histological, biological, and molecular characteristics of adult } \\ \text { recurrent glioma [35] }\end{aligned} \\ \text { RANO Liquid Biopsies } & \begin{array}{l}\text { Review of literature on liquid biopsies for diagnosis and monitoring of } \\ \text { leptomeningeal and parenchymal brain metastases [36] }\end{array}\end{array}$

recent advances in neuro-oncology clinical trial design,

accrual, and conduct in clinical trials.

\section{Clinical trial design}

- Window of opportunity clinical trial designs, in which tumor tissue is sampled from patients pre-treated with the experimental agent, allow us to determine tumor tissue penetration as well as the biochemical, physiologic, and molecular effects of the agent [ $6 \bullet]$.

- Master protocols help improve the efficiency of clinical trials by creating a common trial infrastructure to test multiple treatments under a single protocol.

Few effective treatments exist for primary and metastatic brain tumors. With a plethora of experimental systemic agents in development for oncologic indications, how do we best choose which drugs to test in brain tumors? Sufficient blood-brain barrier (BBB) penetration is a particular challenge to overcome, and even for drugs that can sufficiently penetrate the $\mathrm{BBB}$, how do we ensure that the drug has the intended biochemical, physiologic, and molecular effects in patients? Phase 0 clinical trials are early (sometimes first-in-human) clinical trials that provide preliminary information about drug pharmacokinetics, target engagement, mechanism of action, and pharmacodynamics to help inform decisions about drug candidate selection and development $[6 \bullet, 38]$. In a window of opportunity trial, study participants may be pre-treated with the experimental agent prior to surgery, thus allowing tissue-based pharmacokinetic and pharmacodynamic assessment. The RANO working group provides consensus guidance regarding the use of Phase 0-like/window of opportunity clinical trial designs in neuro-oncology [6•].

For drugs much further in development, traditional randomized controlled trials represent the gold standard for testing efficacy but are expensive, inefficient, and slow, and answer limited questions [39]. Novel designs such as master protocols aim to increase the efficiency of clinical trials. Master protocols specifically create a common trial infrastructure and design to test multiple hypothesis [40], thus improving efficiency via uniformity and standardization. Types of master protocols include basket 
trials, umbrella trials, and platform trials. In a basket trial, the same targeted therapy is evaluated across different diseases that share a common molecular alteration. For example, a trial of an NTRK inhibitor may allow accrual of different cancers with NTRK fusions, which can be seen in a small subset of adult and pediatric primary and metastatic CNS tumors [41]. In contrast, an umbrella trial evaluates multiple targeted therapies for a single disease stratified by molecular subgroups. Alliance A071701 is a multi-arm phase II genomically guided treatment trial for brain metastases patients [42]. Previously obtained tissue from brain metastases and extracranial sites are screened for molecular alterations associated with sensitivity to the drugs available on study (currently CDK, PI3K/mTOR, and NTRK/ROS1 inhibitors). If determined to harbor such a molecular alteration, then the patient enrolls into the corresponding arm of the trial. Finally, platform trials (also known as multi-arm, multi-stage design trials) are trials that evaluate several treatments in a single disease against a common control group. Examples of platform trials include GBM Adaptive Global Innovative Learning Environment (GBM AGILE) [43], INdividualized Screening trial of Innovative GBM Therapy (INSIGhT) [44], and Neuro Master Match $\left(\mathrm{N}^{2} \mathrm{M}^{2}\right)$ [45]. Adaptive platform trials can continue in a perpetual manner, adding or dropping arms [39]. Some may incorporate Bayesian approaches, which allow the ability to accumulate data in real time to alter the course of the trial, thus allowing for ineffective arms to be dropped sooner and for preferential enrollment to promising arms. Mathematical modeling suggests that the use of Bayesian adaptive designs in glioblastoma (GBM) trials results in trials requiring substantially fewer overall patients [46].

\section{Clinical trial conduct}

- Decentralized clinical trials utilize novel technologies or processes to collect study data, thus allowing the study to be designed around patients and not sponsors or sites [47].

- The COVID-19 pandemic has changed the way we practice medicine and allows us to re-envision the conduct of clinical trials [48].

Traditional clinical trial design generally requires all study-related visits and procedures to be performed at the research site. Because most academic centers are in large urban centers, this creates a barrier for trial participants who live far from these centers and/or do not have the resources to travel. Decentralized clinical trials utilize telemedicine, mobile technologies, and/or local health providers to collect study data [47]. The goal is to make clinical trials easier for patients by reducing the need to travel, thus improving trial accrual and retention. During the COVID-19 pandemic, trial conduct adapted to incorporate decentralized approaches in order to minimize travel and physical contact, including increased use of telemedicine, remote work by research staff, shipping of oral investigational agents, and remote monitoring [47,49]. Such flexibility in clinical trial care was bolstered by guidance by regulatory agencies $[50 \bullet, 51 \bullet$, 
Table 2. Summary of recommendations for neuro-oncology clinical trial eligibility [63]. Reprinted with permission from Lee EQ et al. Neuro Oncol 2020 May 15;22(5):601-612

\begin{tabular}{|c|c|c|}
\hline Criterion & Types of trials & Recommendation \\
\hline Age & $\begin{array}{l}\text { Primary brain } \\
\text { tumor }\end{array}$ & $\begin{array}{l}\text { - Allow children (age } \geq 12 \text { ) to participate in adult trials when disease biology and } \\
\text { clinical course is similar in children and adults } \\
\text { - Allow older patients (age } \geq 65 \text { ) to participate on trials, particularly in diseases } \\
\text { such as GBM where older patients represent a significant portion of the patient } \\
\text { population }\end{array}$ \\
\hline Functional status & $\begin{array}{l}\text { Solid tumor phase } \\
1 \text { trials }\end{array}$ & $\begin{array}{l}\text { - Performance score requirement can be of ECOG } \leq 2 \text { or equivalent KPS of } \geq 60 \text { for } \\
\text { selected Phase } 1 \text { clinical trial based on mechanism of action and expected } \\
\text { toxicity profile. }\end{array}$ \\
\hline \multirow[t]{2}{*}{$\begin{array}{l}\text { Co-morbid } \\
\text { medical } \\
\text { conditions }\end{array}$} & $\begin{array}{l}\text { Primary brain } \\
\text { tumor }\end{array}$ & $\begin{array}{l}\text { - Allow participation of patients with a prior or concurrent history of malignancy } \\
\text { whose natural history or treatment does not have the potential to interfere with } \\
\text { the safety or efficacy assessment of the investigational regimen, rather than } \\
\text { specifying a specific time frame since completion of treatment }\end{array}$ \\
\hline & Immunotherapy & $\begin{array}{l}\text { - Allow patients with select, well-controlled, autoimmune diseases to enroll on } \\
\text { immune checkpoint inhibitor trials, e.g., thyroiditis }\end{array}$ \\
\hline $\begin{array}{l}\text { Concomitant } \\
\text { medications }\end{array}$ & Immunotherapy & $\begin{array}{l}\text { - Allow corticosteroids at baseline but consider limiting maximum total daily } \\
\text { doses of } 2 \text { mg dexamethasone and/or stratification according to } \\
\text { dexamethasone dose in randomized trials }\end{array}$ \\
\hline Long washout & $\begin{array}{l}\text { Primary brain } \\
\text { tumor }\end{array}$ & $\begin{array}{l}\text { - Use } 5 \text { half-lives rather than a } 4 \text { week washout for investigational agent. A } \\
\text { general statement that the patient must have recovered from the effects of prior } \\
\text { treatment would allow for even broader participation. }\end{array}$ \\
\hline $\begin{array}{l}\text { Archival tissue } \\
\text { requirements }\end{array}$ & $\begin{array}{l}\text { Primary brain } \\
\text { tumor }\end{array}$ & $\begin{array}{l}\text { - The amount of tissue required for study enrollment needs a strong rationale and } \\
\text { should be limited to what is necessary }\end{array}$ \\
\hline \multirow[t]{2}{*}{ Laboratory values } & $\begin{array}{l}\text { Primary brain } \\
\text { tumor }\end{array}$ & $\begin{array}{l}\text { - Only the relevant laboratory tests based on the safety profile of the study agent } \\
\text { should be used as the basis for eligibility criteria } \\
\text { - For those laboratory tests included as eligibility criteria, allow for a safe range } \\
\text { above normal parameters }\end{array}$ \\
\hline & Immunotherapy & $\begin{array}{l}\text { - Depending on the trial design and primary outcome, baseline } \mathrm{ALC}>1000 \\
\text { cells } / \mu \mathrm{L} \text { is ideal, but }>500 \text { cells } / \mu \mathrm{L} \text { may be reasonable }\end{array}$ \\
\hline \multirow[t]{2}{*}{ Pathology } & GBM & $\begin{array}{l}\text { - Patients with tumors meeting criteria for "diffuse astrocytic glioma, } \\
\text { IDH-wildtype, with molecular features of glioblastoma, WHO grade IV" should } \\
\text { be allowed to participate on GBM clinical trials } \\
\text { - Patients with IDH-mutant GBM can be included in phase 0/I GBM studies where } \\
\text { efficacy is not primary endpoint or patients can be stratified by IDH status in } \\
\text { randomized studies }\end{array}$ \\
\hline & $\begin{array}{l}\text { Solid tumor } \\
\text { phase } 1 \text { trials }\end{array}$ & $\begin{array}{l}\text { - Patients with primary brain tumors including lower grade gliomas and other rare } \\
\text { CNS tumors should be included in dose escalation phases of solid phase I clinical } \\
\text { trials } \\
\text { - Exploratory expansion cohorts of specific brain tumor histopathology should be } \\
\text { included if there is a biologic rationale for efficacy }\end{array}$ \\
\hline \multirow[t]{2}{*}{ Prior therapy } & Phase I & $\begin{array}{l}\text { - Allow inclusion regardless of prior therapy unless a particular study question } \\
\text { makes the prior therapy relevant } \\
\text { - Allow prior exposure to bevacizumab }\end{array}$ \\
\hline & $\begin{array}{l}\text { Phase } \mathrm{II} / \mathrm{III} \\
\text { recurrent GBM }\end{array}$ & $\begin{array}{l}\text { - When efficacy is an important endpoint and there is a high likelihood that } \\
\text { outcomes may be influenced by prior therapies, strategies to allow broader }\end{array}$ \\
\hline
\end{tabular}


Table 2. (Continued)

\begin{tabular}{|c|c|c|}
\hline \multirow[t]{2}{*}{ Criterion } & Types of trials & Recommendation \\
\hline & & $\begin{array}{l}\text { enrollment include specifying separate analyses for patients who have or have } \\
\text { not received the particular treatment (e.g., bevacizumab refractory versus } \\
\text { bevacizumab naïve), enrolling separate arms for these patient populations, or } \\
\text { stratifying randomization based on prior exposure. }\end{array}$ \\
\hline \multirow[t]{2}{*}{$\begin{array}{r}\text { Number of } \\
\text { relapses }\end{array}$} & $\begin{array}{l}\text { Recurrent GBM } \\
\text { and phase I }\end{array}$ & $\begin{array}{l}\text { - Allow any number of prior relapses, especially in phase } 0 / I \text { trials and especially in } \\
\text { bevacizumab-naïve patients }\end{array}$ \\
\hline & $\begin{array}{r}\text { Recurrent GBM } \\
\text { and phase II }\end{array}$ & - Allow at least 2 prior relapses in bevacizumab-naïve patients \\
\hline
\end{tabular}

52-54]. Which (if any) of these flexible policies will continue after the pandemic is unclear.

Policies supportive of telemedicine driven by COVID-19 [55] led to the increased use of telemedicine in oncologic clinical care [49]. However, to sustain widespread use of telemedicine after the pandemic, legislative and policy changes are needed to resolve ongoing issues such as reimbursement, disparities in access, cross-state medical licensure, and cross-state medical malpractice coverage.

Procurement of imaging on study also shifted from central sites to local sites. While more convenient for the patient, this created additional work for study teams given time and effort to collect and review imaging centrally as well as the variability in the quality of imaging in the community. To overcome this obstacle, study sites can develop partnerships with qualified local sites [56] who can follow standardized imaging protocols for primary brain tumor trials

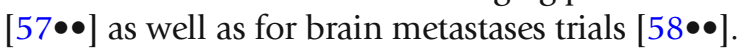

\section{Clinical trial accrual and enrollment}

- Despite their important role in finding better treatments for patients, accrual to oncology clinical trials (including neuro-oncology) is generally poor.

- SNO, RANO, patient advocacy groups, clinical trial cooperative groups, and other partners are working together to improve clinical trial accrual.

Studies suggest that more than $50 \%$ of patients will enroll when offered a clinical trial for which they meet eligibility criteria [59]. However, a survey of brain tumor patients and caregivers revealed that only $21 \%$ participated in a clinical trial and only $24 \%$ were even informed about clinical trial options at the time of diagnosis [60]. In addition, a survey of neuro-oncology providers revealed that less than $30 \%$ of patients were even referred by their provider for a clinical trial [61]. In response to these sobering statistics, SNO, RANO, patient advocacy groups, clinical trial cooperative groups, and other partners banded together to improve trial accrual and enrollment.

The group's first task was to explore the barriers to neuro-oncology trial

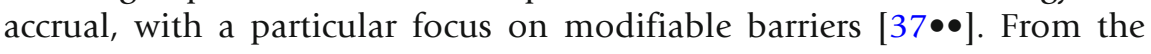


perspective of patients and caregivers, barriers to clinical trial participation include lack of awareness of trial opportunities, misconceptions about research participation, and cost and travel constraints, as well as study burden and inconvenience. Gathering input from patients during the clinical trial design process as well as decentralization of clinical trials may be helpful in developing more patient-friendly clinical trials. In the USA, age, race, gender, and socioeconomic status influence treatment delivery in glioblastoma [62]. Racial bias and mistrust in the medical community may impact the enrollment of underrepresented minorities. Recommendations for improving diversity in study populations include community outreach and education of providers on gender and racial disparities.

The group next re-examined clinical trial eligibility for brain tumor studies [38]. Table 2 summarizes consensus recommendations for neuro-oncology clinical trial eligibility. Overly restrictive eligibility criteria may impair trial accrual, limit patient access to investigational treatments, and limit generalizability [64]. Overly permissive eligibility criteria may increase the risk of harm to patients. In general, eligibility criteria should be tailored depending on the study population, the toxicity and mechanism of action of the study agent, the phase of the study, and the objectives of the study. For example, only the relevant laboratory tests based on the safety profile of the study agent should be used as the basis for eligibility criteria. The group also recommended expanding eligibility criteria for GBM trials when appropriate to include patients with diffuse astrocytic glioma, IDH-wildtype, with molecular features of glioblastoma, WHO grade IV [65].

\section{Summary}

Various groups within the neuro-oncology community continue efforts to improve the accrual, design, conduct, and interpretability of clinical trials. Working groups within RANO, including iRANO and RANO-BM, continue to validate and refine their initial radiographic response criteria. The National Brain Tumor Society held a workshop in July 2020 on innovating brain tumor clinical trials based on lessons learned from the COVID-19 experience with participation from various stakeholders including the US Food and Drug Administration (FDA), academic and community clinicians, researchers, industry, clinical research organizations, patients and patient advocates, and representatives from SNO and the National Cancer Institute [48]. Consensus recommendations from the workshop include further development of virtual neurooncologic assessment, evaluation of which clinical trial elements can be decentralized, and more widespread adoption of the standardized imaging

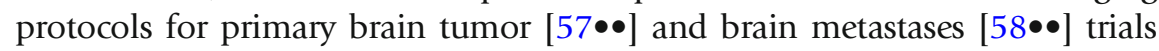
to support enhanced imaging expertise in the community setting.

\section{Declarations}

Conflict of Interest

Eudocia Q. Lee has received honoraria from MedLink, prIME Oncology, and the American Academic of 
Neurology (Continuum), and receives royalties from Wolters Kluwer Health (UpToDate).

\section{References and Recommended Reading}

Papers of particular interest, published recently, have been highlighted as:

- Of importance

$\bullet \quad$ Of major importance

1. van den Bent MJ, Vogelbaum MA, Wen PY, Macdonald DR, Chang SM. End point assessment in gliomas: novel treatments limit usefulness of classical Macdonald's Criteria. J Clin Oncol. 2009;27(18):2905-8. https:// doi.org/10.1200/jco.2009.22.4998.

2. Wen PY, Macdonald DR, Reardon DA, Cloughesy TF, Sorensen AG, Galanis E, et al. Updated response assessment criteria for high-grade gliomas: response assessment in neuro-oncology working group. J Clin Oncol. 2010;28(11):1963-72.

3. van den Bent MJ, Wefel JS, Schiff D, Taphoorn MJ, Jaeckle K, Junck L, et al. Response assessment in neurooncology (a report of the RANO group): assessment of outcome in trials of diffuse low-grade gliomas. Lancet Oncol. 2011;12(6):583-93. https://doi.org/10.1016/ S1470-2045(11)70057-2.

4. Reardon DA, Galanis E, Degroot JF, Cloughesy TF, Wefel JS, Lamborn KR, et al. Clinical trial end points for high-grade glioma: the evolving landscape. NeuroOncology. 2011;13(3):353-61. https://doi.org/10. 1093/neuonc/noq203.

5. Galanis E, Wu W, Cloughesy T, Lamborn K, Mann B, Wen PY, et al. Phase 2 trial design in neuro-oncology revisited: a report from the RANO group. Lancet Oncol. 2012;13(5):e196-204. https://doi.org/10.1016/ S1470-2045(11)70406-5.

6. Vogelbaum MA, Krivosheya D, Borghei-Razavi H, Sanai N, Weller M, Wick W, et al. Phase 0 and window of opportunity clinical trial design in neuro-oncology: a RANO review. Neuro Oncol. 2020;22(11):1568-79. https://doi.org/10.1093/neuonc/noaa149

RANO provides recommendations regarding standardization of clinical protocols for phase $0 /$ window of opportunity studies in neuro-oncology.

7. Okada H, Weller M, Huang R, Finocchiaro G, Gilbert MR, Wick W, et al. Immunotherapy response assessment in neuro-oncology: a report of the RANO working group. Lancet Oncol. 2015;16(15):e534-42. https://doi.org/10.1016/S1470-2045(15)00088-1.

8. Warren KE, Poussaint TY, Vezina G, Hargrave D, Packer RJ, Goldman S, et al. Challenges with defining response to antitumor agents in pediatric neuro-oncology: a report from the response assessment in pediatric neuro-oncology (RAPNO) working group. Pediatr Blood Cancer. 2013;60(9):1397-401. https://doi.org/ 10.1002/pbc. 24562.

9. Warren KE, Vezina G, Poussaint TY, Warmuth-Metz M, Chamberlain MC, Packer RJ, et al. Response assessment in medulloblastoma and leptomeningeal seeding tumors: recommendations from the Response Assessment in Pediatric Neuro-Oncology committee. NeuroOncology. 2018;20(1):13-23. https://doi.org/10. 1093/neuonc/nox087.

10. Erker C, Tamrazi B, Poussaint TY, Mueller S, MataMbemba D, Franceschi E, et al. Response assessment in paediatric high-grade glioma: recommendations from the Response Assessment in Pediatric Neuro-Oncology (RAPNO) working group. Lancet Oncol. 2020;21(6):e317-e29. https://doi.org/10.1016/s14702045(20)30173-x.

11. Fangusaro J, Witt $\mathrm{O}$, Hernáiz Driever $\mathrm{P}$, Bag AK, de Blank P, Kadom N, et al. Response assessment in paediatric low-grade glioma: recommendations from the Response Assessment in Pediatric Neuro-Oncology (RAPNO) working group. Lancet Oncol. 2020;21(6):e305-e16. https://doi.org/10.1016/s14702045(20)30064-4.

12. Cooney TM, Cohen KJ, Guimaraes CV, Dhall G, Leach $\mathrm{J}$, Massimino $\mathrm{M}$, et al. Response assessment in diffuse intrinsic pontine glioma: recommendations from the Response Assessment in Pediatric Neuro-Oncology (RAPNO) working group. Lancet Oncol. 2020;21(6):e330-e6. https://doi.org/10.1016/s14702045(20)30166-2.

13. Lin NU, Lee EQ, Aoyama H, Barani IJ, Baumert BG, Brown PD, et al. Challenges relating to solid tumour brain metastases in clinical trials, part 1: patient population, response, and progression. A report from the RANO group. Lancet Oncol. 2013;14(10):e396-406. https://doi.org/10.1016/S1470-2045(13)70311-5.

14. Lin NU, Wefel JS, Lee EQ, Schiff D, van den Bent MJ, Soffietti R, et al. Challenges relating to solid tumour brain metastases in clinical trials, part 2: neurocognitive, neurological, and quality-of-life outcomes. A report from the RANO group. Lancet Oncol. 2013;14(10):e407-16. https://doi.org/10.1016/ S1470-2045(13)70308-5.

15. Lin NU, Lee EQ, Aoyama H, Barani IJ, Barboriak DP, Baumert BG, et al. Response assessment criteria for brain metastases: proposal from the RANO group. Lancet Oncol. 2015;16(6):e270-e8. https://doi.org/ 10.1016/S1470-2045(15)70057-4.

16. Camidge DR, Lee EQ, Lin NU, Margolin K, Ahluwalia MS, Bendszus M, et al. Clinical trial design for systemic agents in patients with brain metastases from solid tumours: a guideline by the Response Assessment in Neuro-Oncology Brain Metastases working group. 
Lancet Oncol. 2018;19(1):e20-32. https://doi.org/10. 1016/S1470-2045(17)30693-9.

17. Alexander BM, Brown PD, Ahluwalia MS, Aoyama $\mathrm{H}$, Baumert BG, Chang SM, et al. Clinical trial design for local therapies for brain metastases: a guideline by the Response Assessment in Neuro-Oncology Brain Metastases working group. Lancet Oncol.

2018;19(1):e33-42. https://doi.org/10.1016/s14702045(17)30692-7.

18. Chamberlain M, Soffietti R, Raizer J, Ruda R, Brandsma $\mathrm{D}$, Boogerd W, et al. Leptomeningeal metastasis: a Response Assessment in Neuro-Oncology critical review of endpoints and response criteria of published randomized clinical trials. Neuro-Oncology. 2014;16(9):1176-85. https://doi.org/10.1093/ neuonc/nou089.

19. Chamberlain M, Junck L, Brandsma D, Soffietti R, Rudà $\mathrm{R}$, Raizer J, et al. Leptomeningeal metastases: a RANO proposal for response criteria. Neuro-Oncology. 2016. https://doi.org/10.1093/neuonc/now183.

20. Le Rhun E, Devos P, Boulanger T, Smits M, Brandsma $\mathrm{D}$, Rudà $\mathrm{R}$, et al. The RANO Leptomeningeal Metastasis Group proposal to assess response to treatment: lack of feasibility and clinical utility and a revised proposal. Neuro-Oncology. 2019;21(5):648-58. https://doi.org/ $10.1093 /$ neuonc/noz024.

21. Kaley T, Barani I, Chamberlain M, McDermott M, Panageas K, Raizer J, et al. Historical benchmarks for medical therapy trials in surgery- and radiationrefractory meningioma: a RANO review. Neuro-Oncology. 2014;16(6):829-40. https://doi.org/10.1093/ neuonc/not330.

22. Rogers L, Barani I, Chamberlain M, Kaley TJ, McDermott M, Raizer J, et al. Meningiomas: knowledge base, treatment outcomes, and uncertainties. A RANO review. J Neurosurg. 2015;122(1):4-23. https://doi. org/10.3171/2014.7.JNS131644.

23. Nayak L, DeAngelis LM, Brandes AA, Peereboom DM, Galanis E, Lin NU, et al. The Neurologic Assessment in Neuro-Oncology (NANO) scale: a tool to assess neurologic function for integration into the Response Assessment in Neuro-Oncology (RANO) criteria. NeuroOncology. 2017;19(5):625-35. https://doi.org/10. 1093/neuonc/nox029.

24. Avila EK, Chamberlain M, Schiff D, Reijneveld JC, Armstrong TS, Ruda R, et al. Seizure control as a new metric in assessing efficacy of tumor treatment in lowgrade glioma trials. Neuro-Oncology. 2017;19(1):1221. https://doi.org/10.1093/neuonc/now190.

25. Thibault I, Chang EL, Sheehan J, Ahluwalia MS, Guckenberger M, Sohn MJ, et al. Response assessment after stereotactic body radiotherapy for spinal metastasis: a report from the SPIne response assessment in Neuro-Oncology (SPINO) group. Lancet Oncol. 2015;16(16):e595-603. https://doi.org/10.1016/ s1470-2045(15)00166-7.

26. Laufer I, Lo SS, Chang EL, Sheehan J, Guckenberger M, Sohn MJ, et al. Population description and clinical response assessment for spinal metastases: part 2 of the
SPIne response assessment in Neuro-Oncology (SPINO) group report. Neuro-Oncology. 2018;20(9):1215-24. https://doi.org/10.1093/ neuonc/noy047.

27. Arvold ND, Armstrong TS, Warren KE, Chang SM, DeAngelis LM, Blakeley J, et al. Corticosteroid use endpoints in neuro-oncology: Response Assessment in Neuro-Oncology Working Group. Neuro-Oncology. 2018;20(7):897-906. https://doi.org/10.1093/ neuonc/noy056.

28. Dirven L, Armstrong TS, Blakeley JO, Brown PD, Grant $\mathrm{R}$, Jalali R, et al. Working plan for the use of patientreported outcome measures in adults with brain tumours: a Response Assessment in Neuro-Oncology (RANO) initiative. Lancet Oncol. 2018;19(3):e173e80. https://doi.org/10.1016/s1470-2045(18)300044.

29. Armstrong TS, Dirven L, Arons D, Bates A, Chang SM, Coens $\mathrm{C}$, et al. Glioma patient-reported outcome assessment in clinical care and research: a Response Assessment in Neuro-Oncology collaborative report. Lancet Oncol. 2020;21(2):e97-e103. https://doi.org/ 10.1016/s1470-2045(19)30796-X.

30. Albert NL, Weller M, Suchorska B, Galldiks N, Soffietti $\mathrm{R}$, Kim MM, et al. Response Assessment in NeuroOncology working group and European Association for Neuro-Oncology recommendations for the clinical use of PET imaging in gliomas. Neuro-Oncology. 2016;18(9):1199-208. https://doi.org/10.1093/ neuonc/now058.

31. Law I, Albert NL, Arbizu J, Boellaard R, Drzezga A, Galldiks N, et al. Joint EANM/EANO/RANO practice guidelines/SNMMI procedure standards for imaging of gliomas using PET with radiolabelled amino acids and [(18)F]FDG: version 1.0. Eur J Nucl Med Mol Imaging. 2019;46(3):540-57. https://doi.org/10.1007/s00259018-4207-9.

32. Galldiks N, Albert NL, Sommerauer M, Grosu AL, Ganswindt U, Law I, et al. PET imaging in patients with meningioma-report of the RANO/PET Group. NeuroOncology. 2017;19(12):1576-87. https://doi.org/10. 1093/neuonc/nox112.

33. Galldiks N, Langen KJ, Albert NL, Chamberlain M, Soffietti R, Kim MM, et al. PET imaging in patients with brain metastasis-report of the RANO/PET group. Neuro-Oncology. 2019;21(5):585-95. https://doi.org/ 10.1093/neuonc/noz003.

34. Vogelbaum MA, Jost S, Aghi MK, Heimberger AB, Sampson JH, Wen PY, et al. Application of novel response/progression measures for surgically delivered therapies for gliomas: Response Assessment in NeuroOncology (RANO) Working Group. Neurosurgery. 2012;70(1):234-43; discussion 43-4. https://doi.org/10.1227/NEU. 0b013e318223f5a7.

35. Haider AS, van den Bent M, Wen PY, Vogelbaum MA, Chang S, Canoll PD, et al. Toward a standard pathological and molecular characterization of recurrent glioma in adults: a Response Assessment in Neuro- 
Oncology effort. Neuro-Oncology. 2020;22(4):450-6. https://doi.org/10.1093/neuonc/noz233.

36. Boire A, Brandsma D, Brastianos PK, Le Rhun E, Ahluwalia M, Junck L, et al. Liquid biopsy in central nervous system metastases: a RANO review and proposals for clinical applications. Neuro-Oncology. 2019;21(5):571-84. https://doi.org/10.1093/neuonc/ noz012.

37.• Lee EQ, Chukwueke UN, Hervey-Jumper SL, de Groot JF, Leone JP, Armstrong TS, et al. Barriers to accrual and enrollment in brain tumor trials. Neuro Oncol. 2019;21(9):1100-17. https://doi.org/10.1093/ neuonc/noz104

This paper examines barriers to accrual and enrollment in brain tumor trials and offers possible solutions.

38. Burt T, Young G, Lee W, Kusuhara H, Langer O, Rowland $\mathrm{M}$, et al. Phase $0 /$ microdosing approaches: time for mainstream application in drug development? Nat Rev Drug Discov. 2020;19(11):801-18. https://doi. org/10.1038/s41573-020-0080-x.

39. Adaptive platform trials: definition, design, conduct and reporting considerations. Nat Rev Drug Discov. 2019;18(10):797-807. https://doi.org/10.1038/ s41573-019-0034-3.

40. Park JJH, Siden E, Zoratti MJ, Dron L, Harari O, Singer J, et al. Systematic review of basket trials, umbrella trials, and platform trials: a landscape analysis of master protocols. Trials. 2019;20(1):572. https://doi.org/10. 1186/s13063-019-3664-1.

41. Drilon AE, DuBois SG, Farago AF, Geoerger B, GrilleyOlson JE, Hong DS, et al. Activity of larotrectinib in TRK fusion cancer patients with brain metastases or primary central nervous system tumors. J Clin Oncol. 2019;37(15_suppl):2006. https://doi.org/10.1200/ JCO.2019.37.15_suppl.2006.

42. Brastianos PK, Twohy E, Anders CK, Iafrate AJ, Kaufman PA, Cohen JV, et al. Alliance A071701: Genomically guided treatment trial in brain metastases. J Clin Oncol. 2020;38(15_suppl):TPS2573-TPS. https://doi.org/10.1200/JCO.2020.38.15_suppl. TPS2573.

43. Alexander BM, Ba S, Berger MS, Berry DA, Cavenee WK, Chang SM, et al. Adaptive global innovative learning environment for glioblastoma: GBM AGILE. Clin Cancer Res. 2018;24(4):737-43. https://doi.org/10. 1158/1078-0432.Ccr-17-0764.

44. Alexander BM, Trippa L, Gaffey S, Arrillaga-Romany IC, Lee EQ, Rinne ML, et al. Individualized Screening Trial of Innovative Glioblastoma Therapy (INSIGhT): a Bayesian adaptive platform trial to develop precision medicines for patients with glioblastoma. JCO Precis Oncol. 2019;3. https://doi.org/10.1200/po.18.00071.

45. Wick W, Dettmer S, Berberich A, Kessler T, Karapanagiotou-Schenkel I, Wick A, et al. N2M2 (NOA-20) phase I/II trial of molecularly matched targeted therapies plus radiotherapy in patients with newly diagnosed non-MGMT hypermethylated glioblastoma. Neuro-Oncology. 2019;21(1):95-105. https://doi.org/10.1093/neuonc/noy161.
46. Trippa L, Lee EQ, Wen PY, Batchelor TT, Cloughesy T, Parmigiani $\mathrm{G}$, et al. Bayesian adaptive randomized trial design for patients with recurrent glioblastoma. J Clin Oncol. 2012;30(26):3258-63. https://doi.org/10. 1200/JCO.2011.39.8420.

47. Dorsey ER, Kluger B, Lipset $\mathrm{CH}$. The new normal in clinical trials: decentralized studies. Ann Neurol. 2020;88(5):863-6. https://doi.org/10.1002/ana. 25892.

48. Lee EQ, Selig W, Meehan C, Bacha J, Barone A, Bloomquist E, et al. Report of National Brain Tumor Society Roundtable Workshop on Innovating Brain Tumor Clinical Trials: building on lessons learned from COVID-19 experience. Neuro Oncol, accepted for publication, noab082. https://doi.org/10.1093/ neuonc/noab082.

49. Waterhouse DM, Harvey RD, Hurley P, Levit LA, Kim ES, Klepin HD, et al. Early impact of COVID-19 on the conduct of oncology clinical trials and long-term opportunities for transformation: findings from an American Society of Clinical Oncology Survey. JCO Oncol Pract. 2020;16(7):417-21. https://doi.org/10. 1200/OP.20.00275.

50. $\quad$ US Food and Drug Administration. FDA Guidance on Conduct of Clinical Trials of Medical Products during COVID-19 Public Health Emergency. 2020. https:// www.fda.gov/regulatory-information/search-fdaguidance-documents/fda-guidance-conduct-clinicaltrials-medical-products-during-covid-19-publichealth-emergency. Accessed 02 JUL 2020.

The US FDA provides guidance on the conduct of clinical trials during COVID-19.

51. National Cancer Institute. Interim Guidance for Clinical Trial Activities Affected by the Novel Coronavirus (3/13/20). 2020. https://ctep.cancer.gov/content/ docs/Memorandum_on_Interim_Guidance_for Clinical_Trial_Activities_Affected_by_the_Novel_ Coronavirus-3-13-2020.pdf. Accessed 26 AUG 2020.

The US NCI provides guidance on the clinical trials activities affected by COVID-19.

52. National Cancer Institute. Additional Guidance Regarding Alternative Procedures for Clinical Trials Supported by NCI CTEP and NCORP Affected by the Spread of the Novel Coronavirus (3/23/20). 2020. https:/ctep.cancer.gov/investigatorResources/docs/ Memorandum_on_Additional_Guidance_for Clinical_Trial_Activities_Affected_by_the_Novel_ Coronavirus_3-23-2020.pdf. Accessed 26 Aug 2020.

53. National Cancer Institute. CTEP/NCORP Guidance for Collection of Adverse Events Related to COVID-19 Infection (3/25/20). 2020. https://ctep.cancer.gov/ content/docs/Adverse_Event_Guidance_COVID-19_ Final_3-25-20.pdf. Accessed 26 AUG 2020.

54. National Cancer Institute. Updated Interim Guidance for Shipping Oral IND Agents to Clinical Trial Subjects during the COVID-19 Pandemic (6/2/20). 2020. https://ctep.cancer.gov/content/docs/CTEP_Oral_ IND_Agent_Shipments.pdf. Accessed 28 AŪG 2020. 
55. Panagioti M, Panagopoulou E, Bower P, Lewith G, Kontopantelis E, Chew-Graham C, et al. Controlled interventions to reduce burnout in physicians: a systematic review and meta-analysis. JAMA Intern Med. 2017;177(2):195-205. https://doi.org/10.1001/ jamainternmed.2016.7674.

56. Ellingson BM, Brown MS, Boxerman JL, Gerstner ER, Kaufmann TJ, Cole PE, et al. Radiographic read paradigms and the roles of the central imaging laboratory in neuro-oncology clinical trials. Neuro-Oncology. 2020. https://doi.org/10.1093/neuonc/noaa253.

57.• Ellingson BM, Bendszus M, Boxerman J, Barboriak D, Erickson BJ, Smits M, et al. Consensus recommendations for a standardized Brain Tumor Imaging Protocol in clinical trials. Neuro Oncol. 2015;17(9):1188-98. https://doi.org/10.1093/neuonc/nov095

Consensus recommendations for standardized brain tumor imaging protocol for use in primary brain tumor clinical trials.

58.• Kaufmann TJ, Smits M, Boxerman J, Huang R, Barboriak DP, Weller M, et al. Consensus recommendations for a standardized brain tumor imaging protocol for clinical trials in brain metastases. Neuro Oncol. 2020;22(6):757-72. https://doi.org/10.1093/ neuonc/noaa030

Consensus recommendations for standardized brain tumor imaging protocol for use in brain metastases clinical trials.

59. American Cancer Society Cancer Action Network. Barriers to patient enrollment in therapeutic clinical trials for cancer - a landscape report. 2018. Retrieved from https://www.fightcancer.org/sites/default/files/ National\%20Documents/Clinical-Trials-LandscapeReport.pdf. . https://www.acscan.org/policy-resources/ clinical-trial-barriers. Accessed.

60. Bates AJ, Couillard SA, Arons DF, Yung WKA, Vogelbaum M, Wen PY, et al. HOUT-15. Brain tumor patient and caregiver survey on clinical trials: identifying attitudes and barriers to patient participation. Neuro-Oncology. 2017;19(suppl_6):vi109-vi. https:// doi.org/10.1093/neuonc/nox168.446.
61. Rogers JL, Acquaye A, Vera E, Bates A, Wen PY, Armstrong TS. Provider-reported challenges and barriers to referring patients to neuro-oncology clinical trials: a report from the Society for Neuro-Oncology member survey. Neurooncol Pract. 2020;7(1):38-51. https:// doi.org/10.1093/nop/npz038.

62. Dressler EV, Liu M, Garcia CR, Dolecek TA, Pittman T, Huang B, et al. Patterns and disparities of care in glioblastoma. Neurooncol Pract. 2019;6(1):37-46. https://doi.org/10.1093/nop/npy014.

63. Lee EQ, Weller M, Sul J, Bagley SJ, Sahebjam S, van den Bent $\mathrm{M}$, et al. Optimizing eligibility criteria and clinical trial conduct to enhance clinical trial participation for primary brain tumor patients. Neuro-Oncology. 2020;22(5):601-12. https://doi.org/10.1093/neuonc/ noaa015.

64. Kim ES, Bruinooge SS, Roberts S, Ison G, Lin NU, Gore $\mathrm{L}$, et al. Broadening eligibility criteria to make clinical trials more representative: American Society of Clinical Oncology and Friends of Cancer Research Joint Research Statement. J Clin Oncol. 2017;35(33):3737-44. https://doi.org/10.1200/JCO.2017.73.7916.

65. Brat DJ, Aldape K, Colman H, Holland EC, Louis DN, Jenkins RB, et al. cIMPACT-NOW update 3: recommended diagnostic criteria for "Diffuse astrocytic glioma, IDH-wildtype, with molecular features of glioblastoma, WHO grade IV". Acta Neuropathol. 2018;136(5):805-10. https://doi.org/10.1007/ s00401-018-1913-0.

\section{Publisher's note}

Springer Nature remains neutral with regard to jurisdictional claims in published maps and institutional affiliations. 